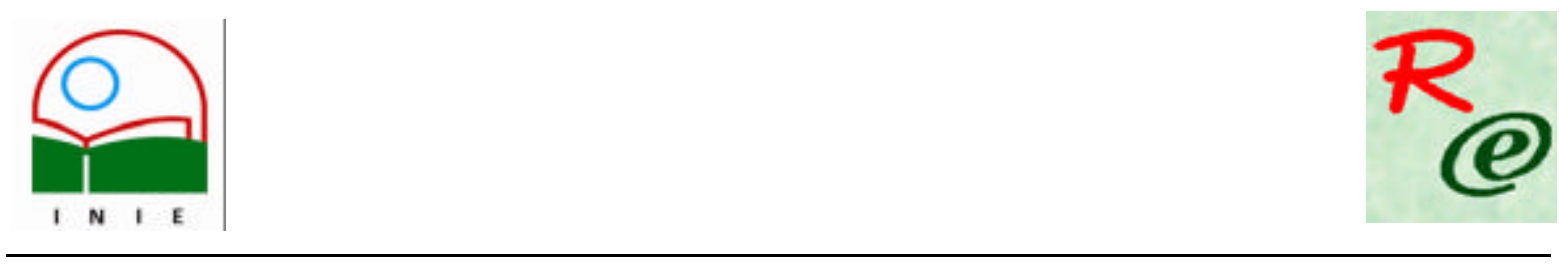

Actualidades Investigativas en Educación

Revista Electrónica publicada por el

Instituto de Investigación en Educación

Universidad de Costa Rica

ISSN 1409-4703

http://revista.inie.ucr.ac.cr

COSTA RICA

\title{
LA EDUCACIÓN EN UN CONTEXTO MEDIÁTICO: \\ LA APROPIACIÓN EDUCATIVA DE LAS TELENOVELAS JUVENILES
}

EDUCATION IN THE CONTEXT OF THE MEDIA:

THE EDUCATIONAL APPROPRIATION OF YOUTHORIENTED SOAP OPERAS

Volumen 9, Número 1

pp. 1-31

Este número se publicó el 30 de abril 2009

Marisol Gutiérrez Rojas

La revista está indexada en los directorios:

LATINDEX, REDALYC, IRESIE, CLASE, DIALNET, DOAJ, E-REVIST@S,

La revista está incluida en los sitios:

REDIE, RINACE, OEI, MAESTROTECA, PREAL, HUASCARAN, CLASCO 


\title{
LA EDUCACIÓN EN UN CONTEXTO MEDIÁTICO: LA APROPIACIÓN EDUCATIVA DE LAS TELENOVELAS JUVENILES EDUCATION IN THE CONTEXT OF THE MEDIA: THE EDUCATIONAL APPROPRIATION OF YOUTHORIENTED SOAP OPERAS
}

\section{Marisol Gutiérrez Rojas ${ }^{1}$}

\begin{abstract}
Resumen: Este documento es una reseña temática de lo planteado en los capítulos introductorios de la tesis doctoral en educación "La apropiación educativa de las telenovelas en los procesos educomunicativos formales. Una lectura desde las percepciones de un segmento de la población adolescente escolarizada urbana costarricense", de Marisol Gutiérrez Rojas. El objetivo es dar cuenta del desarrollo de una experiencia de articulación entre dos prácticas polisémicas: la educación y la comunicación. En este marco se revisan: 1) El conocimiento y comprensión de los medios y sus productos en la educación formal y en la cotidianidad de las personas adolescentes. 2) La relación entre el discurso y la práctica educativas, a partir del modelo $\notin$ comunicación con el otro, con quien se produce conocimiento. 3) Otras textualidades diferentes del libro y de aquellos saberes que se consideran como legítimos o "enseñables", en este caso las telenovelas juveniles, con el afán de revisar y explorar supotencial como objeto de una apropiación educativa.
\end{abstract}

Palabras claves: EDUCOMUNICACION, ADOLESCENTES, MEDIOS, APROPIACION EDUCATIVA, TELENOVELAS JUVENILES.

\begin{abstract}
This is an abstract of the critical analysis written in the introductory chapters of the doctoral thesis on education "The educative appropiation of the soap-opera in the formal education-communication processes". A reading from the perceptions of a segment of the costarican, adolescent, scholarized, urban population", by Marisol Gutièrrez Rojas. This is to report the development of an experience of articulation between two polisemic praxis: education and communication. In this frame the following subjects are analized: 1) The knowledge and comprehension of the media and its products on the formal educational system and the daily life of adolescents. 2) The relationship between the discourse and the educative praxis, considering the model of communication with the "Other", with whom knowledge is produced. 3) Other contents different from the one included in books and from those knowledges considered as legitimate or "teachables", as is the case of the juvenile soup-opera, in order to revise and explore its potential as subject of an educative appropriation..
\end{abstract}

Key words: EDUCATION-COMMUNICATION, ADOLESCENT, MEDIA, EDUCATIVE APPROPIATION, JUVENILE SOAP-OPERA.

\footnotetext{
Doctora en Educación, Máster en Literatura Latinoamericana, ambos títulos de la Universidad de Costa Rica. Actualmente es Docente de la Escuela de Estudios Generales e investigadora de la Universidad de Costa Rica.
}

Dirección electrónica: marigu62@hotmail.com

Artículo recibido: 21 de octubre, 2008

Aprobado: 2 de abril, 2009 


\section{Introducción}

Las páginas siguientes exploran la articulación entre dos prácticas polisémicas: las ciencias de la educación y las ciencias de la comunicación. Esta articulación expresa la combinación recíproca y dialógica, no yuxtapuesta, de ambas prácticas, gracias a la cual se forman y dotan de sentido las dos disciplinas; de ahí que se reconozcan tanto sus especificidades como las relaciones que expresan entre sí y con el contexto.

Es esta articulación la que nos permite hablar de educomunicación, de procesos educomunicativos y de educomunicadores. Cuando hablamos de procesos educomunicativos nos referimos a los tradicionalmente llamados procesos de enseñanza aprendizaje -que tanto en el discurso como en la práctica responden la mayor parte de las veces a relaciones dicotómicas ${ }^{2}$-, y esto nos lleva también a renombrar a las y los docentes como educomunicadoras y educomunicadores. Esta visión se apoya en una larga tradición de educomunicadores entre quienes sobresalen los nombres de Paulo Freire, Mario Kaplún, Francisco Gutiérrez, Daniel Prieto, Guillermo Orozco, Ismar Soãres de Oliveira, Jorge A. Huergo, quienes han entendido la educación allende las aulas y la comunicación como espacio de producción de sentidos y más allá del uso instrumental de los medios.

En el marco de esta reflexión, la educación y la comunicación son asumidas como espacios donde las personas se forman como sujetos sociales y producen significados, es decir, pasan del yo -de la individualidad- al diálogo, o sea, al intercambio y la comunicación con otros, lo cual nos remite a un contexto sociocultural. El actual, marcado por las huellas del desarrollo tecnológico y sus nuevos sistemas simbólicos, implica un reto especial para el quehacer educativo, pues obliga a propuestas ágiles, capaces de analizar y responder a los desafíos de la sociedad emergente, en la cual lo sensorial, lo dinámico, lo emotivo y las narrativas audiovisuales ocupan un lugar destacado (Ferrés, 2000).

Las y los jóvenes, sujetos de la educación, conforman una población fuertemente atraída por la oferta massmediática, aquella que alude al sistema clásico de medios de comunicación (televisión, radio, prensa) más la informática, y con cierta resistencia a las propuestas, en

\footnotetext{
${ }^{2}$ Pensamos, por ejemplo, en dicotomías como las de razón-emoción, intelecto-entretención, docenteestudiante, cultura oficial-cultura popular, discurso adultocéntrico-discurso joven. Volumen 9, Número 1, Año 2009, ISSN 1409-4703
} 
forma y contenido, que ofrece la educación formal, es decir, el espacio educativo institucionalizado.

Lo anterior nos ha motivado para revisar estos aspectos: 1) El conocimiento y comprensión de los medios y sus productos en la educación formal y en la cotidianidad de las personas adolescentes. 2) La relación entre el discurso y la práctica educativas, a partir del modelo de comunicación con el otro, con quien se produce conocimiento. 3) Otras textualidades diferentes del libro y de aquellos saberes que se consideran como legítimos o "enseñables", en este caso las telenovelas juveniles, con el afán de revisar y explorar su potencial como objeto de una apropiación educativa.

\section{El qué, el cómo, y el para quién desde la educomunicación}

Es claro que los medios, en ese flujo continuo, sin clausura, que expone la vida cotidiana mediante lenguajes y códigos de acceso que, en palabras de Jesús Martín Barbero (2002), descolocan los saberes, desplazan las fronteras entre razón e imaginación, entre saber e información, se convierten en un reto para la educación, pero también en una escuela paralela de gran incidencia en la formación de las y los jóvenes. De ahí que uno de los grandes debates se instale precisamente en el cuestionamiento de la educación formal como "legítima" transmisora de saberes y como espacio privilegiado para la socialización, producción, reconocimiento e inclusión de las y los jóvenes (Reguillo, 2000).

Dada esta problemática, conviene reflexionar sobre la propuesta educativa formal vigente, y en particular, sobre el quehacer docente, esto es, lo que estamos haciendo, los modelos de comunicación, estilos didácticos y métodos, instrumentos y tecnologías que ponemos en práctica con las personas con quienes compartimos la construcción del conocimiento; y asimismo, re-mirarlas, re-conocerlas, para que no se conviertan en ese otro sobre quien sabemos poco o nada, aún cuando constituye la razón de ser de nuestro trabajo.

Por lo anterior, el cómollevamos a cabo estos procesos y el qué hacemos en este devenir son también aspectos que debemos considerar en una propuesta de educomunicación. Por eso, cuando miramos a esas y esos jóvenes, sus ideas, sus cotidianidades y sus percepciones sobre el entorno, la mirada educomunicativa debe tener presente que todo lo Volumen 9, Número 1, Año 2009, ISSN 1409-4703 
que se recabe será parte de los insumos para nuestro trabajo, no simples datos que, de tener tiempo, eventualmente aprovecharíamos.

En este sentido, conocer el contexto sociocultural donde se desenvuelven las y los jóvenes, sus consumos mediáticos, los nuevos lenguajes audiovisuales, las nuevas narrativas, las nuevas formas de lectura, de socialización y de conocimiento son indispensables para ejercer una efectiva labor educomunicativa. ¿Qué les interesa a las y los jóvenes?, ¿qué leen y cómo leen?, ¿qué les cautiva?, ¿qué destrezas y habilidades desarrollan fuera del colegio (y sin darnos cuenta)?, ¿en qué actividades invierten sus horas de ocio?, ¿cómo se apropian de las nuevas tecnologías de la información y de la comunicación?, ¿cómo se relacionan con los medios? Estas son algunas de las muchas preguntas que podemos hacernos como docentes $\mathrm{y}$, a lo mejor, las respuestas evidencien un desconocimiento no solo de lo que las y los jóvenes hacen y consumen, sino tam bién de nuestros saberes.

En el caso de los medios de comunicación de masas su vinculación con la cotidianidad del aula no puede soslayarse. Sin embargo, sabemos que no todas las instituciones educativas cuentan con una plataforma tecnológica, y si la tenen, su uso es instrumental, de apoyo o refuerzo, pero pocas veces el motor mismo del conocimiento. Esta subutilización puede responder también a prejuicios en relación con los medios y sus contenidos. Por ejemplo, escuchamos a menudo estas censuras: la televisión y la Internet solo difunden basura, hay que limitar las horas frente al televisor y a la computadora, existen otras actividades más interesantes y educativas, etcétera.

Además de los prejuicios negativos hay una ausencia de criterios para hacer de los medios un vehículo de conocimiento, no solo de información. Por ejemplo, ¿cuántas veces nos hemos planteado promover en las y los estudiantes sus capacidades comunicativas mediante la confección de un blog?; ¿desarrollar sus habilidades de investigación a partir del análisis de los intertextos presentes en un anime?; ¿estimular su apreciación por la diversidad y la multiculturalidad con base en una canción de Calle 13?; ¿ampliar su concepto de lectura a partir de la noción de hipertexto o estimular su comunicación escrita con la creación de un guión para telenovelas juveniles, por citar algunos ejemplos? 
Esta relación con los medios y sus contenidos también puede ampliarse al manejo de aparatos tecnológicos, al aprendizaje del uso de la cámara de video o de las computadoras, o bien a la producción de materiales como un periódico, una revista, un boletín, etc. Esto sería ideal, pero nuestra formación docente dista del desarrollo de estas competencias. Aún se mantienen separados los saberes en educación y en comunicación, y medianamente se acercan en los cursos sobre tecnologías educativas ${ }^{3}$.

Estar a tono con los requerimientos y las competencias que debemos tener como educadoras y educadores del Siglo XXI significa, entonces, superar la visión instrumental de la comunicación, en lo pedagógico y en lo didáctico, y asumir su articulación, la que reiteramos, alude a un diálogo con los medios y con las nuevas tecnologías de la información y la comunicación y, a la vez, al conocimiento de los saberes, intereses y consumos culturales de las y los jóvenes con quienes participamos en los procesos educomunicativos.

\section{Educación y medios de comunicación}

Hablar de educación y de comunicación, en un contexto marcado por megatendencias como la globalización, implica enfrentar nuevos desafíos, entre ellos, vincular el hecho educativo con los medios de comunicación y sus productos, y también con las posibilidades reales de participación y expresión de la gente joven en lo que hacen, dicen y difunden estos medios.

Según lo señalado por la Federación de Organizaciones de Defensa de Derechos de los Niños, Niñas y Adolescentes en Costa Rica (COSECODENI), en su Informe alternativo presentado ante el Comité de Derechos del Niño de las Naciones Unidas (1998-2003), del

\footnotetext{
${ }^{3}$ Por ejemplo, un valioso esfuerzo de la UCR (Facultad de Educación) es el Programa de Tecnologías Educativas Avanzadas (PROTEA), que surge como respuesta a las necesidades de generar un proceso de educación continua en el manejo de tecnologías digitales de la información y la comunicación (TICs) por parte de docentes y estudiantes. Este proyecto ha permitido importantes alianzas con la Fundación Omar Dengo, investigadores del Laboratorio de Medios del Instituto Tecnológico de Massachussets (MIT Media Lab), y transnacionales como INTEL, entre otras instancias. Otra acción interesante, en el plano curricular, es el curso Pedagogía y tecnologías que ofrece la Escuela de Formación Docente. De carácter obligatorio para las carreras de Bachillerato y Licenciatura en Educación Preescolar y Primaria, este curso semestral explora en las aplicaciones de la tecnología en la educación: televisión, videograbadora, retroproyector, video, videoconferencia, videojuegos, aplicaciones multimediales. Sin embargo, estos dos ejemplos apuntan hacia las tecnologías digitales más que hacia un uso general de medios. 
año $2004^{4}$, la participación adolescente en los medios de comunicación es muy limitada. Esto obedece fundamentalmente a las siguientes razones:

- Los prejuicios de las personas adultas en relación con el valor de las opiniones de las personas adolescentes, juzgadas como inmaduras, desinformadas o apáticas. Esto hace que la decisión de qué decir, ver o consumir quede relegada al juicio de los adultos, sean estos la familia, la escuela o los medios, marcados estos últimos por intereses comerciales.

- La desconfianza e indiferencia de las personas jóvenes hacia los medios de comunicación, cimentada en la polarización política y en la baja calidad de la oferta de entretenimiento.

Esta situación sin duda contraviene los esfuerzos emprendidos, sobre todo a partir de los años 90, por garantizar que las personas adolescentes sean aceptadas como sujetos de derechos. Sin embargo, la realidad indica un medio adverso, teñido de prejuicios o de intereses comerciales, carencia de recursos económicos para la formulación de proyectos inclusivos, y evidentemente una ausencia de espacios de consulta y participación de las y los jóvenes, genuinamente estimulada por los medios y el mundo adulto en general.

Por otra parte, el informe de la Federación señala una ausencia de contenidos educativos en la oferta mediática. Sirva esta preocupación para subrayar algunos puntos, por ejemplo: ¿cuál es el concepto de educación que se maneja en la crítica que se hace a los medios?, ¿cuál es el concepto de educación asumido en los productos calificados como 'educativos' producidos por estos mismos medios?

En ocasiones, las críticas a los medios responden a una visión chata, academicista y moralizante de la educación, y bajo esta misma óptica, se producen programas que lejos de estimular el consumo de las personas jóvenes, las alejan y desmotivan. Por esta razón es que la incorporación de la mirada de las personas jóvenes es vital, no solo para la

$4 \quad$ Revisar documento en siguiente dirección: http://www.crin.org/docs/resources/treaties/crc.39/Costa\%20Rica ngo report(S).doc. particularmente las secciones 3.4.6: Participación de niños, niñas y adolescentes en los medios de
comunicación y 3.4.7: Divulgación de material dirigido a la población infantil. Volumen 9, Número 1, Año 2009, ISSN 1409-4703 
generación de productos mediáticos de divertimento o de reflexión (ojalá incluido el entretenimiento), sino también para su uso con fines educativos formales.

Revisar el papel de los medios en la sociedad y su incidencia en los procesos formativos de las y los adolescentes, supone abrir oportunidades de expresión para que las y los jóvenes revaloren temáticas, tratamientos y uso de medios y de tecnologías, y también, ampliar la mirada y analizar los prejuicios en relación con los productos y con las y los consumidores. Sabemos que la oferta mediática (y la publicidad que la acompaña) es pobre en diversidad temática y calidad audiovisual; que la entretención se nutre de violencia, de contenidos pornográficos, de miradas intrusivas; pero también, debemos asumir que hay un divorcio entre la responsabilidad de los medios, de la escuela y de la familia y los intereses de las y los jóvenes. Los medios educan o deseducan según desde dónde los analicemos y de acuerdo con el tipo de ser humano que queremos formar.

\section{1. Educación y televisión}

¿Cómo entender hoy la educación en un mundo globalizado? ¿Cómo prepararnos para trabajar en un mundo signado por una cultura de imágenes, por una "cultura del espectáculo", como declara Joan Ferrés?

En este sentido, el mismo autor plantea una cuestión interesante:

Si es lamentable que la televisión sea a menudo un mundo de emoción sin reflexión, también lo es que la escuela sea con demasiada frecuencia un mundo de reflexión sin emoción. Si es lamentable que en la televisión haya a menudo un exceso de implicación para un mínimo de explicación, también lo es que en la escuela haya a veces tan poca implicación para tanta explicación. (2000, p. 165)

La relación entre educación formal y medios de comunicación audiovisual, concretamente la televisión, es de encuentros y desencuentros. Lo que para las y los jóvenes es un asunto cotidiano, en la educación formal se excluye o subutiliza como fuente de conocimiento. La educación no puede seguir anclada en el pasado, basta ver, entre otras cosas, las tecnologías que utiliza, los contenidos que aborda, la conformación física de sus aulas y la 
distribución de las y los estudiantes en un espacio que responde a un modelo de comunicación vertical y monologal.

El Estado de la Educación (2005, p. 71) en el apartado denominado Debilidades del sistema desde la óptica estudiantil, señala:

Encuestas realizadas entre desertores del sistema revelan que la mayoría no puede precisar el aporte que obtuvo en la escuela, ni sabe qué le hubiera gustado encontrar mientras permaneció en el sistema. La juventud costarricense dedica más tiempo a ver televisión o a reunirse con amistades (más de cinco horas por semana en ambos casos para el $43 \%$ y el $41,9 \%$ de los entrevistados) o incluso a visitar centros comerciales que a la lectura (menos de dos horas semanales para el $47,6 \%$ ). ${ }^{5}$

Por lo tanto, volviendo a la cita de Ferrés referida al inicio de esta sección, la educación debe repensar algunas de sus prácticas, trascender su discurso y explorar activamente otros paradigmas distintos del logocéntrico. Debe incrementar la vida del aula y la curiosidad de las y los jóvenes estudiantes, de manera que pueda prolongarse el aprendizaje fuera de ella. Educar, informar, entretener, cualidades que a primera vista asignamos a la educación, son también cualidades de los medios, y de estos, hay que rescatar, sin prejuicios, su capacidad de generar productos que educan, a la vez que entretienen. Por eso, es importante que las y los educomunicadores atiendan y entiendan la televisión, su peculiar sistema de códigos (palabra, imagen, sonido), su multiplicidad de géneros, sus posibilidades de capturar y mantener la atención de las audiencias, de propiciar otros saberes y de modificar las percepciones es muy amplia. La puntualización de estos aspectos permitiría una mayor comprensión de los medios en general, y de la televisión en particular, de sus saberes y del potencial educativo del entretenimiento.

\footnotetext{
${ }^{5}$ Ya en la década anterior, Fuenzalida y Hermosilla (1991) señalaban que en América Latina las televisoras programaban entre $50 \%$ y $70 \%$ de narrativa ficcional, lo que desplaza en el consumo popular a la narrativa literaria; y en el mismo tenor, el venezolano Leonardo Padrón, exitoso autor de telenovelas, refería: "En Venezuela si uno agota la edición de un libro de mil o dos mil ejemplares tiene que ponerse muy contento, mientras que cualquier telenovela la ven millones y millones de personas" (Mato, 1999, p. 270).
} 
La televisión no es el adversario que se debe eliminar ni una herramienta didáctica ocasional. La televisión es un producto comercial regido por las leyes del mercado, cierto, pero tiene una alta incidencia en la formación de las y los jóvenes. Por lo tanto, hay que conocerla y asumir sus retos. Uno de estos es que genera emociones, pero esas emociones pueden abrir o cerrar las reflexiones tan apetecidas por el discurso educativo formal. Y la educación, ¿emociona? El mismo Ferrés señala: "el gran reto de la educación en la cultura del espectáculo es enseñar a traducir las emociones en reflexión” (2000, p. 221).

\subsection{Telenovelas educativas: experiencias en América Latina}

La consolidación de la telenovela, "aquel género en el cual, a través de la historia serializada de la construcción de una pareja, entran en tensión el mundo del deseo que mueve la acción de los personajes y el mundo de las "convenciones" que organizan la vida social" (Aprea y Martínez 1996, p. 29), ha comprendido a lo largo de los más de cincuenta años de su existencia no solo modificaciones en contenidos, audiencias, propósitos, duración en el número de capítulos, horarios de transmisión, producción y exportación, sino también, el surgimiento de una creciente y millonaria industria latinoamericana que ha propiciado la modernización técnica y profesional de quienes participan en ella, y el establecimiento de alianzas de coproducción más allá del continente.

Asimismo, se ha modificado la opinión de los críticos de las telenovelas y han surgido especialistas de disciplinas diversas que reconocen su valor como producto cultural (escritores, dramaturgos, sociólogos, semiólogos, filólogos, educadores), lo que ha derivado en la apertura de áreas de investigación en el mundo académico ${ }^{6}$.

Ahora bien, ¿cuáles y cómo han sido algunas experiencias latinoamericanas relativas al uso de las telenovelas como vehículo educativo? México, Venezuela y Brasil son los principales

\footnotetext{
${ }^{6}$ Muestra de esto es lo que podríamos llamar una red continental de estudiosos de las telenovelas, en la que han destacado las acciones del Programa Cultura de la Universidad de Colima (México), la Universidad del Valle (Colombia), la Universidad de Buenos Aires (Argentina), la Universidad de São Paulo y, por supuesto, las tareas emprendidas por la Asociación Latinaomericana de Investigadores de la Comunicación (ALAIC), a través de su grupo temático GT Telenovelas y ficción seriada. Este esfuerzo ha generado un significativo número de publicaciones, entre revistas especializadas y libros, cursos, seminarios y grupos de estudio.
} 
productores de telenovelas, a los que se han sumado en los últimos años Argentina, Colombia, Chile y Perú. Sin embargo, a pesar de estos cambios, las experiencias de producción de telenovelas con clara intención educativa no han sido comunes.

México, gran productor y exportador de telenovelas, vivió en los años setentas, un momento paradigmático. Su experiencia con las telenovelas didácticas llamadas "telenovelas prodesarrollo", series melodramáticas que perseguían la entretención a la vez que conducían un tema educativo con el objeto de promover el desarrollo, se replicó en distintos lugares del mundo. Si bien estas telenovelas, siete en total, no figuraron entre las producciones de más alto rating, a diferencia de las comerciales, arrojaron un balance positivo en las audiencias gracias al tratamiento de temas vinculados con la educación de adultos, la planificación familiar, la paternidad responsable, el papel de la mujer en la sociedad mexicana y la educación sexual de las y los adolescentes, tema de nuestro interés. Las décadas siguientes, ochentas y noventas, no ofrecen aportes significativos en cuanto a telenovelas educativas; el melodrama tradicional sigue siendo la pauta.

En el caso de Venezuela, la tradición heredada por los autores cubanos que se exiliaron tras la Revolución de 1959 marcó una línea de corte tradicional melodramático en la producción venezolana, cuyo mejor exponente es Delia Fiallo. Esta línea varió un poco a raíz de una resolución gubernamental dictada en 1976, que estipulaba la "obligación de transmitir programas culturales por TV" (Mazziotti, p. 1996); de esta forma, surgen las telenovelas culturales de RCTV (Radio Caracas Televisión), en su mayoría adaptaciones de clásicos de la literatura, novelas de época o biográficas, estilo más ligado a la cultura erudita que a lo educativo en un sentido amplio. La participación en estas producciones de dramaturgos de renombre como José Ignacio Cabrujas, Salvador Garmendia e Ibsen Martínez permitió el tratamiento de temas ajenos al esquema tradicional como la independencia de la mujer, el divorcio o conflictos políticos y sociales.

Sin embargo, con el pasar de los años, así como al interior de los dramas de las telenovelas la lucha es entre el bien y el mal, la industria venezolana se ha debatido entre la telenovela rosa y la de contenido social. Algunas experiencias pueden rescatarse, tal es el caso de Por estas calles, una telenovela de lbsen Martínez que se estrenó a inicios de los noventas, que no solo tuvo todas las audiencias posibles, sino que también permitió llevar el pulso político Volumen 9, Número 1, Año 2009, ISSN 1409-4703 
de ese país durante varios años a lo largo de los cuales la audiencia iba construyendo y deconstruyendo el texto para ver en la pantalla una propuesta de lectura de su realidad nacional.

El caso de Colombia es muy interesante. En opinión de Fernando Gaitán, periodista y escritor de las nuevas generaciones, quien saltó a la fama con Café con aroma de mujer (1994) y autor del éxito sin precedentes de Yo soy Betty, la fea (2000), "la TV cumple la función de la literatura, al mirar y recrear las distintas regiones del país, y vamos conociéndonos unos a otros" (Correa, 1998, p. 18). La producción de telenovelas colombianas, primero de consumo local y ahora de vigorosa exportación, se ha nutrido de la riqueza étnica de su pueblo y de la variedad de sus paisajes: entre lo rural y lo urbano los escritores han dado cuenta de las contradicciones sociales de su país. Por lo demás, su estilo paródico, satírico e irónico, ha dado como resultado una exitosa mezcla entre melodrama y comedia, tal es el caso de Yo soy Betty, la fea, de Pedro el escamoso o de Los Reyes.

En lo que respecta a Argentina, en lo señalado por Nora Mazziotti (1996) no se registran experiencias de marcado acento educativo, pero sí resulta interesante detenerse en las reacciones que la telenovela provoca durante la dictadura militar establecida en 1976. Dos fuertes ataques de censura, uno de ellos sobre el formato y los contenidos de las telenovelas, dicen sobre las aprehensiones en torno a la influencia que estos discursos pueden tener en la audiencia y, por lo tanto, el peligro que pueden representar para algunos modos de pensar y de actuar. Alberto Migré, uno de los guionistas más connotados de Argentina, y ya fallecido, se preguntaba por esos días: ¿Acaso porque no se traten el aborto, el adulterio, la infidelidad, dejarán de existir? (Mazziotti, 1996, p. 82). Pregunta interesante, pues nos revela datos importantes referentes a las temáticas sociales abordadas por las telenovelas y, a la vez, sugiere otra pregunta: ¿qué molesta: la telenovela o el uso social de la telenovela?

Finalmente, en Chile, la experiencia con telenovelas cercanas a lo que podría denominarse telenovela educativa transita por diversas épocas y temáticas; un esfuerzo sistematizado y sostenido no ha tenido lugar. Sin embargo, recientemente tanto las televisoras privadas como las estatales han hecho un intento por producir telenovelas que incluyan temas de Volumen 9, Número 1, Año 2009, ISSN 1409-4703 
discusión en la agenda nacional (El circo de las Montini, Machos, Bienvenida realidad ${ }^{\text {) }}$; y han aparecido interesantes ejercicios de "introspección" cultural, geográfica y étnica como Amores de mercado, Pampa llusión, Romané, entre otras. Si bien estas telenovelas no responden de forma explícita a un interés educativo, sí interpelan esta esfera.

Es importante destacar en este recuento de la experiencia chilena, el papel central y de avanzada que tuvo en la década de los ochenta el Centro de Indagación y Expresión Cultural y Artística (CENECA), en lo concerniente al estudio de la recepción activa de los televidentes, la alfabetización televisiva y la formulación de una propuesta de apropiación educativa de las telenovelas. El equipo de investigadores del CENECA, liderado por Valerio Fuenzalida, ideó el Programa de Educación para la Recepción Activa de TV, que tenía como objetivos la educación del receptor y la transformación de la TV a partir de la sociedad receptora. Sin duda, una de las propuestas más novedosas y serias generadas en Latinoamérica y que ha repercutido en la producción de telenovelas, en su consumo y en su estudio.

\subsection{Jóvenes y telenovelas}

La oferta televisiva latinoamericana del último decenio se ha caracterizado por una acelerada producción de programas que buscan la participación activa de las y los jóvenes, tal es el caso de las telenovelas. Este interés ha incidido en la forma y en el contenido de este género; por ejemplo, Carrasco Mery (entrevista personal: Chile 13 nov. 2002) habla de una telenovela "combinada", en alusión a una telenovela donde se cruzan historias, rangos etarios, miradas intergeneracionales, problemáticas particulares y nacionales, la cual puede o no haber sido creada para audiencias juveniles, pero que estas las asumen como propias. Asimismo, otros investigadores, como Gustavo Aprea (1996), hablan de las telenovelas juveniles como textos de iniciación, por cuanto permiten explorar en aquellas situaciones que

\footnotetext{
${ }^{7}$ El circo de las Montini, teleserie dirigida por Vicente Sabatini, fue premiada en 2002 en los Shine Awards, uno de los galardones que entrega The Media Project, una organización sin fines de lucro interesada por el tratamiento de los temas sexuales en televisión. Esta fue la primera telenovela local en tratar por primera vez el tema del sida. Por su parte, Machos, telenovela que aborda los sentimientos de los hombres, toca por vez primera el tema de la homosexualidad; en la misma línea, Bienvenida realidad (2004) plantea el tema del lesbianismo. Volumen 9, Número 1, Año 2009, ISSN 1409-4703
} 
introducen a preadolescentes y jóvenes en los vericuetos del mundo adulto (situación que nos es extraña, por ejemplo, para la literatura y el cine).

Lo anterior nos lleva a los contenidos. Las telenovelas ponen en escena temáticas de interés para la población joven como el primer amor, el embarazo no deseado, las drogas, la anorexia, la gordura, las infidelidades, los problemas escolares, la cesantía, etc. Sin embargo, en algunas producciones aún se nota en el tratamiento de los temas una mirada adultocéntrica. Pero también encontramos esfuerzos por incorporar de forma activa la voz de las y los jóvenes; por ejemplo, Pablo Avila, productor ejecutivo del área dramática de TVN de Chile, declara:

Ahora estamos haciendo una teleserie juvenil y yo ya tengo 36 años. Todos los que estamos aquí estamos bordeando los treinta y tantos y ¿qué es innovar para mí? Elegir un equipo de guionistas, pero también es asesorarte por jóvenes de 14 y 16 . La mirada tiene que ser de ellos, no de nosotros (Wikén, 2002 p.15. El destacado es nuestro).

La consideración de esa "mirada" es esencial, porque declara una actitud inclusiva obviamente mediatizada por el interés de asegurar el éxito de la telenovela, pues estamos hablando de televisión comercial-, que de todas formas apunta hacia la incorporación activa de las audiencias jóvenes, cada vez más interesadas por espacios donde miren y puedan ser mirados.

Fuenzalida señala, para el caso de las telenovelas, que "estas brindan a las y los jóvenes la oportunidad de vivir "modelos anticipatorios" de conflictos afectivos y situaciones vitales que sienten en el presente o que presienten que vivirán en el futuro" (1993, p. 9). Al ser las conductas afectivas relevantes en las narraciones, se vuelven fundamentales en los procesos de identificación y reconocimiento que se originan con personajes y con actores y actrices. Por lo demás, estos últimos saltan indistintamente de los escenarios de la canción a los de la actuación o de los concursos de belleza a las telenovelas, en un gesto múltiple de visibilización.

Un breve recuento de las producciones de telenovelas latinoamericanas da cuenta de lo anteriormente señalado. En México, por ejemplo, la creciente oferta de telenovelas dirigidas a una audiencia juvenil incluye, entre otras: Pobre juventud (1987), Quinceañera (1988), Volumen 9, Número 1, Año 2009, ISSN 1409-4703 
Dulce desafío (1989), Muchachitas (1991), Mágica juventud (1992), Agujetas de color rosa (1994), Amigas y rivales (2001), El juego de la vida (2001) y Clase 406 (2002). Esta última, nominada a los Shine Awards por su contribución en el tratamiento de temas sobre salud sexual y reproductiva. El nuevo siglo presenta un giro en la inclusión de temas que pasan por la exploración de conflictos familiares, académicos, afectivos y de clase social. La oferta comercial no decae y surgen éxitos como Rebelde (2004), versión de la telenovela argentina Rebelde way, donde los protagonistas cantan y bailan. Esta combinación (canto, baile y actuación) es cada vez más frecuente en las telenovelas juveniles latinoamericanas, pues, entre otras cosas, permite hacer una promoción cruzada: cuando se oye la canción en la radio, se la asocia con la telenovela, y a la vez, abre una oportunidad de multiexpresión para las y los jóvenes.

En Venezuela, de los mismos productores y escritores de Por estas calles, surgen dos éxitos juveniles posteriores: A todo corazón (1997), que arrasó con el rating en Venezuela, Centroamérica, Estados Unidos, Bolivia y Chile y Así es la vida (1998). Sin embargo, en Venezuela continúa primando la telenovela comercial marcada por las coproducciones internacionales, los protagonistas que cantan y bailan, como en Jugando a ganar (1998), y una que otra exploración en temas polémicos, como es el caso de Juana la virgen (2002), que narra la historia de una adolescente quien, por un error médico, es sometida a una inseminación artificial y queda embarazada siendo virgen.

Asimismo, vinculadas con la oferta dirigida a audiencias juveniles, se destacan en Colombia dos interesantes producciones: el reality show Protagonistas de novela (2002), en el que competía un grupo de jóvenes aspirantes a actores y actrices, y Francisco el matemático (1999), que nació con la idea de incidir en un cambio de actitud y comportamientos juveniles. El punto de partida fue una investigación realizada por el Instituto Distrital de Educación (IDEP), que recopiló historias y anécdotas de aproximadamente 40 docentes de escuelas públicas de Bogotá ${ }^{8}$. Francisco el matemático tuvo su versión mexicana: Clase 406 y otra chilena titulada 16. En el año 2003, Francisco el matemático obtuvo el Shine Awards por su contribución al sano desarrollo de la salud sexual.

\footnotetext{
${ }^{8}$ Para mayor información visitar la página:

http://www.comminit.com/la/descripciones/lapdscolom/descripciones -640-html. Volumen 9, Número 1, Àño 2009, ISSN 1409-4703
} 
Ya en la década de los ochentas, en Argentina, con el regreso de la democracia, se consolida la temática juvenil y la participación de las y los jóvenes. Clave de sol (1986) fue la primera telenovela protagonizada por adolescentes; desde entonces, las y los jóvenes se han incorporado activamente como técnicos, asistentes de producción y como actrices y actores, en muchos casos protagónicos. De los últimos tiempos, cabe destacar las telenovelas juveniles Montaña rusa (1994), Amigovios (1995), Rebelde way (2002) у Floricienta (2005). Las dos últimas son proyectos que combinan actuación y música, y que han trascendido los límites de la pantalla chica en giras internacionales para promocionar las bandas musicales y los discos. Todas estas producciones exploran el mundo de los afectos, la construcción de proyectos de vida, los conflictos académicos, la discriminación y la fantasía. $Y$ en Chile, el creciente interés por atender las audiencias juveniles, no solo por un asunto de marketing desde el punto de vista de "creación de demanda", sino también por satisfacer necesidades afectivas -a través de vivencias y modelos de la vida cotidiana presentes en el verosímil televisivo-, ha propiciado el surgimiento de una teleserie con rasgos particulares. De nuevo el criterio de Fernando Carrasco Mery resulta elocuente:

Desde los años 90 y en la dirección de telenovelas con Sabatini se han podido observar distintos tipos de jóvenes, con formas de hablar, vestirse y de relación muy diversas. Los jóvenes de Chiloé, de la Isla de Pascua, los que viven en el circo, los que vivían en la pampa a comienzos del siglo pasado, son muy diferentes a los jóvenes de Santiago y estos son muy diferentes entre sí, depende de dónde están ubicados social y culturalmente. Quizá lo común es el "flujo amoroso" donde el amor imposible, el amor con dificultades y el amor que se concreta, atraviesa todas las historias. Creo que lo similar con otros jóvenes de otras producciones latinoamericanas está en las tensiones con el mundo adulto y las normativas que ellos imponen y que, obviamente, intentan transgredir. La problemática de Misael en la telenovela chilena El circo de las Montini es diferente en relación a la clase social de Mel en la telenovela brasileña El clon y a Jimena en la telenovela mexicana Amigas y rivales -el chico pobre y las niñas son hijas de millonarios- pero, son similares en la problemática de jóvenes que consumen o han consumido drogas ilícitas. (Comunicación personal, Gutiérrez, 2002).

Finalmente, encontramos en este panorama una telenovela nicaragüense: Sexto sentido. Producida por la ONG Puntos de Encuentro, sale al aire en el año 2001. En estricto rigor, Volumen 9, Número 1, Año 2009, ISSN 1409-4703 
más que una telenovela es una teleserie que aborda a lo largo de 80 capítulos las vivencias de un grupo de jóvenes y de adolescentes enfrentados a situaciones diversas, pero comunes a la población joven centroamericana. La exploración de temas vinculados a las relaciones familiares, de pareja, a la construcción de proyectos de vida, problemas con drogas y alcohol, situaciones de riesgo como la transmisión del VIH-SIDA, el abuso y acoso sexual, así como temas vinculados a minorías, como el de la homosexualidad, le ha generado una gran acogida. En el 2004 es reconocida con el Shine Awards en la categoría Premio Especial de Educaentretenimiento Latino, por su tratamiento del tema de la salud sexual de la población adolescente. Esta iniciativa llevada a cabo en un país con una trayectoria incipiente en producción televisiva nacional y pionero en telenovelas, con un equipo de producción y un elenco joven, incluso algunos adolescentes, llega a Costa Rica en setiembre de 2005, donde se transmite una vez por semana por canal 15 de la UCR .

Este mapeo de las producciones de telenovelas juveniles latinoamericanas, significativo por la cantidad y variedad de la oferta, por los temas que atiende y por los reconocimientos de que han sido objeto algunas de las producciones en tanto contribuyen en temas sensibles, tales como la salud, podría alertar sobre la pertinencia de una relectura de estas narrativas audiovisuales que permita resignificarlas en el espacio educativo formal. Pero además, resultan interesantes porque constituyen espacios de participación de las y los jóvenes, no solo como consumidores, sino también como protagonistas de tareas que comprenden la actuación, el diseño y la generación de productos culturales mediáticos que forman parte de aquello en lo que se reconocen, identifican y emocionan.

\footnotetext{
${ }^{9}$ Ver Gutiérrez Rojas (2007). "Jóvenes: consumos y producciones culturales”. En Reconociendo(nos). Escuela de Estudios Generales, Universidad de Costa Rica. El artículo refiere, entre otras cosas, la experiencia vivida en el año 2005 en el marco de un curso de Humanidades donde, a partir del visionado de esta telenovela, se abordó el tema de la migración y el de la xenofobia. Volumen 9, Número 1, Año 2009, ISSN 1409-4703
} 


\section{La apropiación educativa de las telenovelas}

Valerio Fuenzalida (1996) apunta que ocurre un natural proceso de apropiación educativa de distintas propuestas televisivas: la audiencia percibe, experimenta e interpreta los significados y les asigna valores (sentidos) desde su propio mundo de significaciones. Gracias a esta condición de televidencia activa se puede extraer un subproducto desde el interior de un texto de entretención (en este caso la telenovela), a partir de aquello con lo que nos identificamos, reconocemos y emocionamos

Pero, ¿por qué interesarnos por la posibilidad de efectuar una apropiación educativa de las telenovelas juveniles en los procesos educomunicativos formales, y más específicamente, desde las percepciones de las y los adolescentes?

Retomemos algunas razones que adelantamos páginas atrás:

- El cuestionamiento que se hace a la educación formal como "legítima" transmisora de saberes, en una sociedad como la actual, atravesada por una revolución tecnológica que desplaza fronteras y propicia la gestación de nuevas textualidades y de novedosas formas de socialización y de adquisición de conocimientos.

- El tono del discurso y de la práctica educativa de la educación formal, que favorece la construcción de la dicotomía cognición/emoción. Se vive en paralelo y no en diálogo lo afectivo y lo cognitivo, y prevalece una concepción monologal y unidireccional de la comunicación, donde los espacios para la expresión (creatividad, criticidad), la autoexpresión (placer, disfrute) y la interlocución (socialización, solidaridad) son reducidos.

- El papel central de la población joven como destinataria y consumidora de muchos de los nuevos productos tecnoculturales, caracterizados por "la potenciación de lo sensorial, de lo narrativo, de lo dinámico, de lo emotivo y de lo sensacional" (Ferrés, 2000, p. 24).

- La emergencia de una creciente y variada oferta de telenovelas juveniles que, aunada a sus características retóricas, temáticas y de enunciación, parecen brindar a las y los adolescentes atractivos cercanos a sus intereses y entornos. 
- La aún incipiente cartera de indagaciones sobre el mundo adolescente $^{10}$, y en especial, sobre sus relaciones con los medios de comunicación de masas ${ }^{11}$.

- El tema de las percepciones. En opinión de Fuenzalida y Hermosilla, "la percepción no es solo sensorial, implica representaciones del pasado (evocaciones) y del futuro (fantasía lúdica, planeadora, configuradora, creativa)" (1991, p. 29), de ahí que se diga que la percepción es construida con intereses y sentimientos. Así, las percepciones son marcadas por la subjetividad de las personas y por sus mediaciones o influencias (escuela, familia, grupo de pares, iglesia, etc.) las cuales, a su vez, inciden en la apropiación que, en este caso, las y los jóvenes hagan de las telenovelas. Preguntarse entonces por las percepciones que las y los adolescentes tienen de las telenovelas, con el afán de analizar sus significaciones y considerarlas para su aprovechamiento en los procesos educomunicativos formales tiene implicaciones importantes para la educación. Primero, validar las percepciones de las y los adolescentes ${ }^{12}$, esto es, su experiencia, interpretación y valoración del mundo; segundo, entender que esas percepciones están asociadas a procesos no solo cognitivos sino también afectivos, los que a la vez están atravesados por distintas mediaciones, de ahí la riqueza y diversidad de interpretaciones, visiones y perspectivas; y tercero, reconocer que las y los adolescentes se relacionan activamente, desde su propio mundo de significaciones, con la propuesta televisiva.

\footnotetext{
${ }^{10}$ Cabe subrayar que la preocupación por las juventudes es reciente. A partir de los años noventa se da una interesante generación de estudios, prioritariamente hacia temas de legislación, políticas públicas, participación política, y poco sobre estudios culturales juveniles, como serían las temáticas sobre movimientos, contraculturas, formas de agruparse y uso de medios. Por otra parte, si bien su quehacer enfatiza el tema de derechos, los esfuerzos del Programa Interdisciplinario de Estudios y Acción Social de los Derechos de la Niñez y la Adolescencia (PRIDENA) de la Universidad de Costa Rica, creado en 2002, constituye un aporte significativo con el valor agregado del trabajo en redes.

${ }^{11}$ Se consultaron los proyectos y publicaciones del Instituto de Investigación en Educación (INIE), del Instituto de Investigaciones Sociales (IIS) y del Instituto de Investigaciones Psicológicas (IIP), todos de la UCR, pero las investigaciones en esta área son incipientes. Cabe destacar, sin embargo, los proyectos de investigación y las publicaciones del académico del IIP, Rolando Pérez, y las iniciativas del IIS como la Jornada de Investigación sobre Juventud (abril 2002/UCR), interesante muestra de investigaciones con una perspectiva culturalista y acercamientos metodológicos cualitativos. En el año 2006, esta investigadora inscribe en el INIE el proyecto Consumos culturales de adolescentes escolarizados urbanos № 724-A7-074, con el propósito de abonar en la reflexión de esta temática.

${ }_{12}$ Aproximadamente 523.646 personas, $12 \%$ de la población total del país: 4.401 .849 , según datos del Instituto Nacional de Estadística y Censos, Encuesta de Hogares de Propósitos Múltiples 2006.
} 
En correspondencia con los objetivos, los fundamentos teóricos de la investigación y en consonancia con la población con la cual hemos decidido trabajar: adolescentes escolarizados urbanos, la investigación se diseñó en los siguientes términos.

\subsection{Estrategia metodológica}

Participantes:

Estudiantes adolescentes (hombres y mujeres), con edades comprendidas entre los 13 y los 16 años, de dos colegios académicos diurnos pertenecientes al Cantón de Curridabat, Circuito 3, Distrito 1, uno público (Liceo de Curridabat) y otro privado (Colegio Internacional Canadiense).

La muestra dirigida estuvo conformada por 39 personas. Para el caso del Colegio Internacional Canadiense: 21 personas: 14 mujeres y 7 varones. En el caso del Liceo de Curridabat: 19 personas: 10 mujeres y 9 varones.

Luego de obtenidos los permisos respectivos con la dirección de las instituciones, se hizo la convocatoria de participación en el taller Mirar (nos) en las telenovelas. Las telenovelas desde las percepciones de los y las adolescentes. Se usó un cartel y se abrió la inscripción voluntaria; sin embargo, en ambas instituciones se optó por privilegiar la participación de estudiantes con mejores promedios y buena conducta.

\section{Procedimiento de recolección de datos}

Cuestionario. Se llevó a cabo una reunión previa a la ejecución del taller para explicar las particularidades de la actividad, llenar el consentimiento informado y administrar un cuestionario de 29 ítems que sirviera como perfil de entrada del grupo y para comparar las respuestas del cuestionario (orden del decir) con lo dicho y lo hecho en la experiencia vivencial y reflexiva que tendría lugar en el taller.

Taller. Se programó para un total de cinco horas, distribuidas en dos días de la misma semana lectiva. En cada día se efectuó una sesión de dos horas y media, y comprendió la combinación de diversas técnicas: 
Grupos de discusión para atender aportes individuales y grupales (consensos y disensos) a partir de preguntas encaminadas a detectar sus percepciones en relación con los ejes temáticos: 1) educación/comunicación, 2) adolescentes, 3) telenovelas. Visionado ${ }^{13}$ de fragmentos de telenovelas juveniles seleccionadas (editadas en VHS), con el objeto de examinar de forma crítica una muestra de la oferta televisiva. La selección del corpus de telenovelas juveniles se hizo en atención a la oferta presentada por los canales comerciales costarricenses con base en los siguientes criterios: ser consideradas por la industria televisiva como telenovelas juveniles en función de la edad del elenco, las temáticas que abordan, el público meta al que van dirigidas y el horario de programación. Las tres telenovelas escogidas para el visionado fueron: Clase 406 (México), El juego de la vida (México), Rebelde way $(\text { Argentina })^{14}$.

Juegos de simulación con el objetivo de que a partir del "jugar a ser como" experimentaran por sí mismos la ficción televisiva y exploraran sus capacidades expresivas, creativas y reflexivas, se les propuso la elaboración de un capítulo de telenovela a partir de sus propios intereses. Se les suministró un ejemplo de guión de telenovela para que consideraran: título, tema, duración, personajes, espacio y tiempo, y parlamentos de las escenas; asimismo, se les pidió que se distribuyeran los roles, buscaran los materiales para el vestuario y la escenografía y ensayaran las acciones para la filmación que tendría lugar en la siguiente sesión del taller (día 2).

13 Conviene aclarar que a diferencia de algunos autores que entienden por visionado el proceso estricto de mirar televisión (encender, mirar y apagar), la noción que aquí asumimos implica algo más que mirar; nos referimos a una mirada crítica, esto es, describir y analizar temas de interés, actitudes, valores, etc., presentes en los parlamentos y las acciones de los personajes y los contenidos de las telenovelas; las razones por las cuales ven o no telenovelas; sus percepciones sobre las telenovelas; cómo interactúan con las telenovelas; y cómo se perciben como adolescentes en relación con las y los adolescentes que aparecen en las telenovelas.

${ }^{14}$ El juego de la vida cuenta las vivencias de cuatro muchachas adolescentes unidas por un fuerte lazo de amistad, entretejido en los vericuetos del último año de preparatoria y la práctica del fútbol soccer femenino. No hay una pareja protagónica como tal, pero sí está presente el tema del amor. Hay un intento por ponderar el entusiasmo por el deporte y la defensa de los derechos de las y los jóvenes a vivir su vida, de ahí la metáfora del juego, que en realidad es el juego de la propia vida. Rebelde Way narra las vivencias de adolescentes estudiantes del internado Elite Way School, destinado a hijas e hijos de familias adineradas. Las pugnas entre estudiantes becados y los integrantes de La logia permiten explorar el tema de la exclusión, la arrogancia, la intolerancia; pero también, la historia de cuatro estudiantes que, por amor a la música y a pesar de sus diferencias sociales, forman la banda musical Erreway. Clase 406 es una historia de colegiales que aborda los temas del amor y la amistad, las traiciones, los desplantes, la violencia, el aborto, las drogas, las diferencias de clase, la homosexualidad, y la vida de este grupo de jóvenes como estudiantes. Volumen 9, Número 1, Año 2009, ISSN 1409-4703 
Evaluación del taller. Comprendió dos modalidades: una oral en plenario, y otra escrita, individual y anónima, en atención al grado de satisfacción o insatisfacción con la experiencia, conocimientos adquiridos, sugerencias y comentarios.

Triangulación. Se estableció una evaluación permanente de los pasos por seguir a partir del registro de la investigadora y el apoyo de una observadora (observación no participante). Se diseñó una guía de observación en atención a comportamiento verbal y no verbal de los grupos de estudiantes; actitudes corporales y verbales que denotaran tensión, aburrimiento, empatía, interés; participación (activa, interesada)/ pasiva, evasiva); disciplina (aceptable, inaceptable); uso del espacio; asistencia; conducción del taller por parte de la facilitadora.

\section{Procedimiento de análisis}

Para el cuestionario:

- Codificación y categorización de la información suministrada en el cuestionario utilizando SPSS.

- Análisis de la información: elaboración de cuadros de contingencia de acuerdo con las categorías propuestas y el cruce de variables: género y tipo de colegio y cálculo de parámetros estadísticos (uso de chi cuadrado).

- Interpretación de los resultados, los que incluyen observaciones sobre la relación de las variables y tendencias observadas.

Para los talleres:

- Categorización y análisis de la documentación obtenida: oral y textual (escritura, dibujos, esquemas conceptuales, diagramas), en relación con los ejes temáticos de interés: educación/comunicación, adolescencia y telenovelas, discutidas y revisadas por las y los estudiantes de acuerdo con sus propias vivencias.

- Registro y análisis de información oral derivada del visionado de fragmentos de telenovelas: sus percepciones sobre las mismas, sobre los adolescentes que aparecen en estas, sus argumentos en cuanto al uso o no de las telenovelas como recurso didáctico.

- Registro y análisis de los videos de las telenovelas producidas por las y los estudiantes: temas, logros y dificultades. 
- Registro y señalamiento de aspectos considerados como logros y como dificultades del taller de acuerdo con la guía de observación y la evaluación final de las y los estudiantes.

- Análisis comparativo de la información suministrada en el cuestionario (orden del decir) con lo dicho y hecho (orden del decir mediado por el grupo, orden del hacer) en la experiencia vivencial y reflexiva del taller.

\section{Resultados}

Como se señaló en páginas atrás, la aplicación de un cuestionario personal y autoadministrado, previa al taller, obedeció a la necesidad de contar con una aproximación a las percepciones de las y los estudiantes acerca de las telenovelas, que luego sirviera para evaluar posibles modificaciones en esta línea, a raíz de la experiencia vivencial del taller.

En este sentido, los hallazgos más interesantes del cuestionario pueden resumirse de la siguiente manera:

- La telenovela es un género televisivo que no se encuentra entre las preferencias de consumo de las y los adolescentes con quienes trabajamos en esta investigación.

- No existe una actitud acentuada de rechazo ni hacia su programación como parte de la oferta televisiva, ni hacia su consumo o su uso en el ámbito educativo formal.

- Existen prejuicios por parte de los varones para admitir que se ve telenovelas, lo que puede obedecer a la internalización del discurso oficial que estigmatiza estos textos mediáticos y a las relaciones de poder que inciden sobre la construcción de género.

- Hombres y mujeres reconocen las características formales y de contenido de las telenovelas, coinciden en los aspectos que en su criterio determinan la calidad de las producciones (cercanía con la realidad -parecen referirse más bien a verosimilitud- y profundidad en el tratamiento de temas), y en la significación de aquello en lo que consideraron se reconocen o no, les gusta o disgusta, entretiene o irrita.

- En cuanto al uso de las telenovelas para trabajar temas de estudio en el colegio, la información indica cierto rechazo, pues señalan que su condición de fantasiosas, alejadas de la realidad y transmisoras de antivalores, las distancia de lo que, en su opinión, deben ser los objetivos de la educación. 
- Con respecto a la posibilidad de aprender mediante las telenovelas hubo reconocimientos afirmativos, así como la mención de algunos temas viables en este sentido: el manejo de la amistad, de las relaciones con los padres y las madres, las relaciones amorosas, cómo enfrentar problemas sociales como las adicciones, y que pueden convertirse en una forma original y divertida de tratar temas de su interés.

En lo que respecta a la experiencia analítica y vivencial del taller ${ }^{15}$, esta generó una modificación en sus percepciones sobre las telenovelas, de marca positiva, en relación con lo apuntado en el cuestionario. Luego del taller, concluyeron que:

- La oportunidad que en este se les brindó para efectuar una producción de su factura y desde sus propios intereses, les resultó muy atractiva y aportó un plus al análisis del potencial educativo de estas narrativas audiovisuales, a la vez que les estimuló para aprender sobre los lenguajes de la televisión: audio e imagen.

- Encuentran relación entre las narraciones de las telenovelas y la vida real, pero poca profundidad en el tratamiento de los temas (señalan temas sociales, sobre todo en las telenovelas brasileñas). En lo que parecen encontrar una gran semejanza entre realidad y ficción es en los chismes, al ser estos, según sus propias declaraciones, parte de su cotidianidad y de sus prácticas: "Lo único real en las telenovelas es que siempre hay chismes. No solo nosotros. Incluso en los periódicos"(m).

- Reconocen el visionado de las telenovelas como una oportunidad para mirar de forma entretenida temáticas ligadas a sus intereses como jóvenes, algunas de las cuales, en su opinión, no son tocadas en las materias de estudio: las diferencias culturales (dadas por el origen diverso de las producciones), la confrontación del mundo adulto con el mundo de la gente joven, la presencia de estereotipos de género, la influencia del grupo de pares en la toma de decisiones y en la dinámica de sus relaciones, o la reflexión sobre el espectro valórico. En este último punto vale subrayar lo siguiente: si bien las y los estudiantes indicaron que en las telenovelas "hay una falta de valores: irrespeto, infidelidad, complejo de superioridad" (h), el señalamiento sobre la violencia, fuera esta física o verbal, denotó que su realidad, su vivencia personal, está

\footnotetext{
${ }^{15}$ En el caso del colegio público no fue posible efectuar el juego de simulación (Día 2) por problemas de asistencia de las y los estudiantes y porque el espacio destinado para el taller fue utilizado para otras actividades del colegio. En su lugar, se llevó a cabo una entrevista a profundidad con dos estudiantes mujeres. Volumen 9, Número 1, Año 2009, ISSN 1409-4703
} 
marcada también por episodios violentos que se viven bajo una doble moral ${ }^{16}$. Veamos los siguientes ejemplos:

"mentira que uno hace así, yo llego y le doy" (m). La reacción violenta en la realidad puede ser más fuerte que en la ficción televisiva.

"que le pegue metido en el cuarto" $(\mathrm{m})$. Pareciera que el problema no es la violencia sino que no se oculte. ¿Hubieran preferido una escena que muestre la agresión, pero en privado? Si es así, podríamos estar ante una eventual naturalización de la agresión.

"a mi mamá no le he terminado de hablar y me da en la boca" (m). Esta expresión nos hace pensar que la realidad es más violenta que la ficción.

Estos ejemplos pueden convertirse en una valiosa información para las y los docentes, pues nos sitúan ante un escenario de confrontaciones y de contradicciones entre lo que las y los jóvenes reclaman para sí, como trato respetuoso y afectivo, y lo que ellos y ellas actúan y reciben como personas, impresión ques es compartida tanto por las y los estudiantes del colegio público como del privado. Esta observación se ve reforzada con las temáticas abordadas en la telenovela producida en el taller. Los temas, el tratamiento de estos y los personajes fueron seleccionados desde sus propios intereses. Asimismo, los aspectos señalados en la entrevista efectuada a las dos estudiantes del colegio público, donde no pudo efectuarse la dinámica de simulación de una telenovela, apuntan hacia el tema de la violencia.

- Aceptan el uso de las telenovelas para abordar contenidos de estudio, pero sujeto a la calidad de las producciones, calidad que asocian con la verosimilitud de las situaciones y la profundidad en la resolución de los problemas en este género televisivo (las brasileñas son las mejor calificadas por las y los estudiantes de ambos colegios). Propuestas explícitas para su uso no hubo ${ }^{17}$.

\footnotetext{
${ }_{17}^{16}$ Esta situación de nuevo es evidente en las producciones de las telenovelas hec has por estudiantes.

17 La institución educativa legitima o desaprueba algunos saberes, y la telenovela, al ser un género tan estigmatizado, requeriría de un tiempo mayor de relectura y resignificación Ver los interesantes cuestionamientos que hace Nelly Richard a las mediaciones académicas, en especial a lo que denomina "la máquina universitaria", los "saberes legítimos" y al concepto de cultura en "Signos culturales y mediaciones académicas", en Beatriz González Sthephan (comp.). 1996. Cultura y tercer mundo. 1. Cambios en el saber académico. 
- La oportunidad de incursionar en el diseño de una telenovela a partir de sus intereses, experiencia llevada a cabo solo en el colegio privado, les permitió explorar temas, trabajar en grupo y aproximarse a una actitud crítica frente a lo que se mira y a cómo ellas y ellos se miran. El grupo total de participantes se dividió espontáneamente en dos grupos: el de las y los estudiantes de grados superiores, que reprodujo desde su interpretación el esquema tradicional de intrigas y personajes estereotipados, y abordó temas que respondían a sus inquietudes y a su realidad cotidiana (en su opinión no tratados en clases), como son los siguientes:

$>$ Sexualidad

$>$ Infidelidad

$>$ Drogadicción

> Discriminación social

Problemas familiares (agresión)

$>$ Lesbianismo

$>$ Chisme

$>$ Estereotipos

$>$ Rivalidad entre amigos

$>$ Problemas de estudio

$>$ Exclusión

$>$ Incomunicación

$>$ Valores trastocados

El grupo de grados inferiores mantuvo las características formales del género, fue menos diverso en la temática, pero más estructurado en el hilo conductor de la historia. Abordó un solo tema: la incomunicación. Su desenlace fue el suicidio, temática que parecía relatar, de alguna manera, la experiencia de marginación vivida por este grupo de adolescentes en relación con el otro equipo, conformado por estudiantes de grados superiores, cuya conducta podría haberles resultado amenazante. De hecho, la presión de grupo es señalada en la evaluación final por las y los estudiantes como una dificultad. Esto nos sitúa ante una situación similar a la ocurrida en las tres sesiones cortas del inicio del taller, donde entra en juego "la espiral del silencio", esta vez actuada en el suicidio. Los y las estudiantes de grados inferiores, en minoría, frente al grupo de grados superiores que probablemente les 
estimula una sensación de represión y aislamiento que desemboca en el planteamiento de esta temática.

Los temas y el tratamiento de las propuestas formuladas por las y los estudiantes indican la vivencia de una cotidianidad violenta, excluyente y poco solidaria. Su opinión generalizada sobre la forma en que las telenovelas exageran la realidad y su crítica a los finales felices que tienen todas, contrasta con sus propuestas y desenlaces agresivos y dolorosos.

En el colegio público no fue posible realizar la actividad de diseño de una telenovela, en su lugar, se efectuó una entrevista en profundidad con dos estudiantes mujeres que accedieron a hablar sobre las dificultades que se habían presentado ese día, la experiencia del taller y la evaluación de la actividad. Por lo que señalaron, el espacio que se abría para la conversación no solo parecía ser una práctica inusual -como bien habían indicado cuando abordaron en plenario el eje educación-, sino que a la vez les permitía hablar sobre temas no comentados en la institución -a pesar de ser cotidianos en la vida colegial- y que se habían vislumbrado en la primera sesión de trabajo, como la ausencia de diálogo, la no consideración de sus opiniones e intereses, la violencia verbal, así como la mención de otros temas vinculados a carencias de infraestructura o mantenimiento de la existente, el uso mínimo e instrumental de medios audiovisuales, a pesar de que el colegio cuenta con equipo de televisión y VHS, y de las necesidades de las y los estudiantes como son el mejoramiento de las relaciones interpersonales entre las y los profesores y las y los estudiantes, y la satisfacción de una necesidad vital: la alimentación, concretamente el almuerzo.

\section{Mirando el futuro inmediato}

En un siglo como el actual, de la información y del conocimiento, el sistema educativo debe esforzarse por revisar el perfil y la formación de sus docentes, así como el currículum, y convendría hacerlo a la luz del concepto de educomunicación. Formar educomunicadoras y educomunicadores interesados por ese otro con quien trabajan, por sus necesidades, sus expectativas, sus habilidades y destrezas, su tiempo libre, sus consumos mediáticos - aun cuando esto implique un trastoque de los valores del mundo adulto. 
Asimismo, debemos pensar en docentes que impulsen una relación reflexiva e interesada en los medios y sus productos, y que sean capaces de mirarlos no solo como entretenimiento, usualmente ligado este a "intelectualmente débil", sino como un potencial por explorar. Si bien es cierto que un porcentaje significativo de la oferta mediática es banal y de dudosa calidad, esto no puede constituir el punto de partida para su descalificación, pues por encima está, por ejemplo, el innegable lugar que ocupan los medios en las preferencias de consumo de las personas, y en particular de las y los jóvenes. Hay que acercarse a la gente joven y aprender con ella a usar los medios, a leerlos de otra manera, a descubrir sus posibilidades didácticas, a superar el lenguaje verbal y pasar al de la imagen preguntando(les) ¿qué se mira?, ¿desde dónde se mira?, ¿cómo se mira?, ¿qué significados le atribuyen? Esto no solo genera ideas y nuevas experiencias, sino que abre también espacios de diálogo e interlocución tan reclamados por las y los estudiantes.

En un mundo globalizado, los conocimientos y habilidades diversas son claves para el desarrollo. Convendría incursionar en nuevos modos de alfabetización a partir de una nueva noción de lectura: la audiovisual, y pensar en incluir la alfabetización en medios y el trabajo con la TV como materia transversal; asimismo, promover una actitud reflexiva hacia los medios, ojalá acompañada de la generación de productos de factura estudiantil. No podemos perder de vista que el qué depende del cómo, por esto, incorporar las narrativas audiovisuales para estimular múltiples oportunidades y para abordar y analizar de una forma amigable temas que pertenecen a las realidades concretas de las y los jóvenes podría enriquecer los procesos educomunicativos formales. Pero también se requiere de esfuerzos conjuntos, por ejemplo, las escuelas de formación docente podrían establecer alianzas con otras escuelas, como las de Comunicación, de Cine, de Arte (Gráficas, Teatro, Pintura), con el Sistema Nacional de Radio y Televisión Cultural (SINART), o con el Instituto de Desarrollo Profesional Uladislao Gámez, para conocer más sobre medios, tecnologías audiovisuales y multimedia e incluirlos en la malla curricular, fomentar su uso y el consecuente desarrollo de habilidades deseables.

Si bien aquí hablamos de telenovelas, bien puede abordarse el tema de la apropiación educativa con otros géneros televisivos o con otros productos mediáticos. Lo que interesa es el aprovechamiento del contexto con el que dialogan, conviven e interactúan las y los jóvenes. En el caso de las telenovelas, un uso inteligente (desprovisto de prejuicios Volumen 9, Número 1, Año 2009, ISSN 1409-4703 
negativos), ligado al ejercicio de una lectura crítica y reflexiva y a la clara identificación de las necesidades e intereses de las y los jóvenes, puede hacer que estas entretengan, y a la vez eduquen, según los intereses de la educación formal. En buenas cuentas, acercarnos a lo mediático, pero desde las percepciones de las y los jóvenes, en aras de crear espacios espistemológicos y metodológicos más entretenidos, dialógicos y conciliadores con la cotidianidad de estos y estas jóvenes que queremos seducir para el aprendizaje.

Las políticas culturales, que se expresan en políticas educativas y comunicacionales, deben considerar en sus formulaciones lo que está vivo en las culturas. Las políticas educativas y las políticas culturales tienen relación con los consumos culturales de las y los jóvenes con quienes trabajamos. Pero además de los programas que consumen, deben interesar los procesos de significación que de los mismos hacen las y los jóvenes.

Asimismo, sería altamente oportuna la promoción de estudios interdisciplinarios que ayuden a comprender mejor poblaciones tan heterogéneas como las adolescentes, sus prácticas culturales, de adquisición de conocimientos, sus formas de entretenimiento, sus aspiraciones, cualquier aspecto de su vida que incida en la construcción de las y los sujetos de derechos, afán primero de la educación. 


\section{Referencias}

¿Qué es la educomunicación?. Aire comunicación. Recuperado octubre 2005, de http://www.airecomun.com/educo.htm

Almeida, Airton Lorenzoni. (2006, julho). Mídia, educação e cidadania na Aldeia Global: para que mundo estamos educando? UNIrevista, 1 (3) http://www.alaic.net/ponencias/UNIrev Almeida.pdf.

Aparici, Roberto. La educomunicación a comienzos del siglo XXI. Recuperado 1 de abril 2006, http://www.educastur.princast.es/cpr/gijon/recursos/comunicacion/tveducativa2_2.pdf

Aprea, Gustavo y Martínez Mendoza, Rolando C. (1996). Hacia una definición del género telenovela. En Telenovela/telenovelas. Los relatos de una historia de amor (1730). Buenos Aires: Atuel.

Aprea, Gustavo. (1996). Tiras juveniles y telenovela: el caso Montaña rusa En Telenovela/telenovelas. Los relatos de una historia de amor (141-158). Buenos Aires: Atuel

Avila, Pablo. (2002, 26 de diciembre). El triunfo de las teleseries. Periódico El Mercurio (Chile), Revista Wikén, p. 26.

Bisbal, Marcelino. (1998, abril). Desde la otra orilla o pensar pensar la educación desde el espacio de la comunicación. Revista Latina de Comunicación Social, (4) La Laguna, Tenerife http://www.ull.es/publicaciones/latina/z8.

Bujanda, Héctor. (1998, 28 de noviembre) Y se fueron los años 90 . El imperio de las telenovelas no acepta moldes. Periódico El Nacional (Caracas), Sección Espectáculos, p. 1.

Correa Guatarasma, Andrés. (1998, 16 de marzo). Fernando Gaitán: lapidado por el éxito. Periódico EI Universal (Caracas) Sección Espectáculos, p. 18.

Donas Burak, Solum. (2001). Adolescencia y juventud. Viejos y nuevos desafíos en los albores del nuevo milenio. En Adolescencia y juventud en América Latina (23-40). Costa Rica: Libro Universitario Regional.

Federación de Organizaciones de Defensa de Derechos de los Niños, Niñas y Adolescentes en Costa Rica. 2004. Informe alternativo presentado ante el Comité de Derechos del Niño de las Naciones Unidas (1998-2003). Recuperado octubre 2005, de http://www.crin.org/docs/resources/treaties/crc.39/Costa\%20Rica ngo report(S).doc.

Ferrés, Joan. (2000). Educar en una cultura del espectáculo. España: Paidós. 
Fuenzalida, Valerio y María Elena Hermosilla. (1991). El televidente activo. Manual para la recepción activa de T.V. Santiago de Chile: Corporación de Promoción Universitaria/ CENECA.

Fuenzalida, Valerio. (1993). TV broadcasting para el desarrollo. Chasqui (45), 94-100.

Fuenzalida, Valerio. (1996). La apropiación educativa de la telenovela. Dialogos de la Comunicación. (44), 91-104.

Gutiérrez Rojas, Marisol. (2007). Jóvenes: consumos y producciones culturales. En Reconociendo(nos) (33-44). Escuela de Estudios Generales. Universidad de Costa Rica.

Gutierrez Rojas, Marisol. (2008) La apropiación educativa de las telenovelas en los procesos educomunicativos formales. Una lectura desde las percepciones de un segmento de la población adolescente escolarizada urbana costarricense. Tesis de Doctorado en Educación. Universidad de Costa Rica, San José, Costa Rica.

Gutiérrez Rojas, Marisol. (2002, 13 y 27 de noviembre). Comunicación personal. Magister Fernando Carrasco Mery, investigador Universidad de Arte y Ciencias Sociales (ARCIS), Santiago de Chile.

Huergo, Jorge A. (Ed.). (2001). Comunicación/Educación. Ámbitos, prácticas y perspectivas. Buenos Aires: Ediciones de Periodismo y Comunicación.

Instituto de Estudios Sociales en Población (IDESPO). (2005). Percepciones de la ciudadanía costarricense sobre el sistema educativo. Universidad Nacional, Costa Rica.

Kaplún, Mario. 1998. Procesos educativos y canales de comunicación. Chasqui (64), 4-8.

Kaplún, Mario. (1992). A la educación por la comunicación. La práctica de la comunicación educativa. Chile, UNESCO/ORELAC.

Kaplún, Mario. (1997, junio). De medio y fines en comunicación. Chasqui, (58), CIESPAL, Quito. Recuperado en junio 2003, de http://www.comunica.org/chasqui/kaplun.htm.

La iniciativa en comunicación. (2004). Francisco, el matemático, Colombia. Recuperado enero 2004, de http://www.comminit.com/en/node/33700/37.

Martín Barbero, Jesús. (2002, febrero). Jóvenes: comunicación e identidad. Pensar Iberoamericana Revista de cultura, (0). Organización de Estados Iberoamericanos. Recuperado en junio 2003, de http://www.oei.es/pensariberoamerica/ric00a03.htm.

Mato Daniel. (1999). Telenovelas: transnacionalización de la industria y transformaciones del género, En Las industrias culturales en la integración latinoamericana (245283). México: Editorial Grijalbo. 
Mazziotti, Nora. (1993). Estado de las investigaciones sobre telenovela latinoamericana. Revista de Ciencias de la Información, número extraordinario. Editorial Complutense. pp. 45-58.

Mazziotti, Nora. (1996). La industria de la telenovela. La producción de ficción en América Latina. Argentina: Paidós.

Motter, Maria Lourdes. (2000). Telenovela e educação: um proceso interativo. Comunicação y educação, ano $\mathrm{VI},(17)$.

Orozco, Guillermo. (1998). Hacia una pedagogía de la televidencia. Comunicación y Sociedad (32), 169-199.

Pérez, Rolando. (2000-2001). Juventud, uso de medios y tiempo libre. Un estudio con jóvenes de las provincias de San José y Limón. Revista de Ciencias Sociales, (9091). Editorial de la Universidad de Costa Rica. pp. 65-81.

Programa Estado de la Nación en Desarrollo Humano Sostenible. (2005). Estado de la educación costarricense. San José: Programa Estado de la Nación/CONARE.

Programa Estado de la Nación. (2005). Duodécimo Informe Estado de la Nación en desarrollo humano sostenible. San José: Programa Estado de la Nación/CONARE.

Quiroz, María Teresa. (2003, febrero-mayo). Por una educación que integre el pensar y el sentir. El papel de las tecnologías de la información y la comunicación. Pensar Iberoamérica. Revista de Cultura, (3). Organización de Estados Iberoamericanos. Recuperado en junio 2003, de http://www.campusoei.org/pensariberoamerica/ric03a03.htm.

Reguillo Cruz, Rossana. (2000). Emergencia de culturas juveniles. Estrategias del desencanto. Colombia: Grupo Editorial Norma.

Richard, Nelly. (1996). Signos culturales y mediaciones académicas (1-22). En Cultura y tercer mundo. 1. Cambios en el saber académico.

Torres Aguilera, Francisco Javier. (1994). Telenovelas, televisión y comunicación. México: Ediciones Coyoacán S.A.

UNICEF/Universidad de Costa Rica. (2005). V Estado de los derechos de la niñez y la adolescencia en Costa Rica. San José: UNICEF/Universidad de Costa Rica. 